11. Cheburkina, M. (2011). To the problem of the term «French Baroque»: «Baroque music» by J.-J. Rousseau (1768). Musicology. 2. 2-9 [in Russian].

Стаття надійщла до редакції 14.06.2016

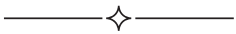

УДК 78.481

Богдан Николаевич Кисляк,

аспирант Львовской национальной

музыкальной академии им. Н. В. Лысенко

bogdankuslyak@gmail.com

\title{
ИНСТРУМЕНТАЛЬНО-ТЕМБРОВАЯ ДРАМАТУРГИЯ СМЕШАННЫХ БАЯННЫХ АНСАМБЛЕЙ
}

Цель данного исследования заключается в рассмотрении творчества композиторов и исполнителей XXI века и одновременно детальном анализе новых тембральных явлений в современном музыкальном искусстве. Методология исследования заключается в использовании комплексного и историко-теоретического методов. Научная новизна. Обзор творчества современных композиторов и исполнителей демонстрирует их немалый интерес к проблеме тембра. Это позволяет утверждать, что в значительной степени такая заинтересованность продиктована разноцветной тембровой палитрой музыки XX - начала ХХІ века. Формирование нового инструментария, усложнения традиционных народных или академических инструментов, новейшие технологии и исполнительские приемы- все эти процессы стали залогом новых тембральных явлений в современном музыкальном искусстве. Выводы. Анализ современной украинской музыкальной литературы для баянных ансамблей позволяет характеризовать тембр как один из важнейших факторов формообразования. Композиторы, создавая ансамбли с участием баяна-аккордеона, формируют композиционный план произведения, учитывая тембровое взаимодействие выбранных инструментов. Таким образом, форма сочинения выстраивается на тембровом противопоставлении, наращивании или полифоническом сочетании различных тембров. Такой процесс указывает на «оркестровость» как способ мышления композиторов при создании подобных ансамблей.

Ключевые слова: представители, тембровая драматургия, баяно-инструментальный жанр.

(C) Кисляк Б. Н., 2016 
Kislyak Bogdan, aspirant of the Lviv National M. V. Lisenko Academy of music

Instrumental-timbre dramaturgy of mixed bayan ensembles

The purpose of work is to examine the creativity of composers and performers of the 21st century and at the same time a detailed analysis of new timbral phenomena in contemporary musical art. The methodology of the study is to use complex and historical-theoretical methods. Scientific novelty. A review of the creativity of contemporary composers and performers demonstrates their considerable interest in the problem of timbre. This allows us to assert that, to a large extent, such interest is dictated by the multicolored timbre of music of the $X X$ - early XXI century. The formation of new tools, the complication of traditional folk or academic instruments, the latest technologies and performing techniques-all these processes have become a pledge of new timbral phenomena in contemporary musical art. Conclusions. Analysis of modern Ukrainian musical literature for bayan ensembles allows us to characterize the timbre as one of the most important factors shaping. Composers, creating ensembles with the bayan-accordion, form the compositional plan of the work, taking into account the timbre interaction of the selected instruments. Thus, the form of the composition is built on a timbre contrast, build-up or polyphonic combination of different timbres. Such a process indicates «orchestration» as a way of thinking of composers when creating such ensembles.

Keywords: representatives, timbre dramaturgy, bayan instrumental genre.

Кисляк Богдан Миколайович, аспірант Львівської національної музичної академії ім. М. В. Лисенка

Інструментально-темброва драматургія змішанних баянних ансамблів

Мета даного дослідження полягає в розгляді творчості композиторів та виконавців ХХІ століття і одночасно детальному аналізі нових тембральних явищ в сучасному музичному мистецтві. Методологія дослідження полягає у використанні комплексного та історико-теоретичного методів. Наукова новизна. Огляд творчості сучасних композиторів і виконавців демонструє їх чималий інтерес до проблеми тембру. Це дає підстави стверджувати, що в значній мірі така зацікавленість продиктована різнобарвною тембровою палітрою музики XX - початку ХХІ століття. Формування нового інструментарію, ускладнення традиційних народних або академічних інструментів, новітні технології і виконавські прийоми - всі ці процеси стали запорукою нових тембральних явищ в сучасному музичному мистецтві. Висновки. Аналіз сучасної української музичної літератури для баянних ансамблів дозволяє характеризувати тембр як один з найважливіших чинників формоутворення. Композитори, створюючи ансамблі з участю баяна-акордеона, формують композиційний задум твору, враховуючи темброву взаємодію вибраних інструментів. Таким чином, форма твору вибудовується на тембровому 
протиставленні, нарощуванні або поліфоничному поєднанні різних тембрів. Такий процес вказує на «оркестровість» як спосіб мислення композиторів при створенні подібних ансамблів.

Ключові слова: представники, темброва драматургія, баянно-інструментальний жанр.

Актуальность темы исследования. В процессе изложения музыкального материала за тембром закрепляется определенная эмоциональная сфера, что в процессе развития с другими тембрами-носителями выстраивает драматургию произведения. На примере современных украинских баянных ансамблей можно утверждать, что тембровая драматургия стала одним из главных формообразующих принципов.

Существующие исследования в данной отрасли баянной ансамблевой музыки не содержат исчерпывающего анализа, рассеянного в эпизодических научных исследованиях. Поэтому основной проблемой данной статьи являются обобщения исследований из этой темы, а также необходимость в системной, исторической и социокультурной реконструкции процесса становления и развития смешанного баянного ансамблевого искусства.

Анализ исследований и публикаций. Этой теме посвящен ряд работ. В частности М. Имханицкого [4], И. Ергиева [2], Е. Назайкинского [5], А. Мирека [8], Л. Поникаровой [9] и других. В украинском музыковедении вопросом тембровой драматургии посвящены труды Д. Кужелева [7], Е. Иванова [3], М. Давидова [1], С. Коробецкой [6] и др.

Цель данного иследования заключается в рассмотрении творчества композиторов и исполнителей XXI века и одновременно детальном анализе новых тембральных явлений в современном музыкальном искусстве

Изложение основного материала. Раскрытие драматургических и стилеобразующих функций тембра невозможно без определения самого понятия «тембр». Как физическое явление, тембр имеет большое количество характеристик, состоящих из объективных показателей. На звучание инструмента влияют различные факторы: корпус инструмента, возбудитель звука, акустика и тому подобное. Распространенное в теоретических трудах определение тембра как «окраски» звука, что связано с высотой, динамикой и длительностью, является достаточно поверхностным и не соответствует современному пониманию явления. В XX веке тембр рассматривают не столько как сопутствующее интонации явление, сколько как физическое, акустическое. 
Понятие автономии тембра для музыки последнего столетия стало привычным. Приобретая самостоятельное значение, тембр отмежевывается от интонационных источников, образуя новые явления. Функция тембра приобретает самодостаточное значение. Эти проблемы в теоретических работах отмечались неоднократно. Е. Назайкинский в книге «Звуковой мир музыки» отмечает, что «в музыке $\mathrm{XX}$ века колористичность звучания и композиционная логика... так или иначе взаимодействуют с интонацией, но нередко отодвигают ее на задний план» $[5,163]$.

Музыкальная драматургия, в отличие от формы, направлена на раскрытие образов в движении, развитии, взаимодействии и борьбе, то есть последовательно раскрывает этапы становления музыкальной мысли. Драматургия в музыке взаимодействует с формой, выстраивая архитектонику целого. Сцепление отдельных отрывков единой логикой музыкального развития и рождает драматургический план. Выявление такой драматургии (в том числе и тембровой) исполнителем на предыдущем этапе должно дать толчок использованию арсенала профессиональных навыков.

С понятием тембровой драматургии тесно связано и выявление семантики тембров как элемент стилевой системы современной музыки. Украинский музыковед С. Коробецкая определяет элементы этого аспекта: «тембровая выразительность и тембровая экспрессия, оркестровая изобразительность и звукопись, картинность, оркестровый колорит, красочность, в музыке XX века добавляется темброзвучность (сонорность)» $[6,57]$. С. Коробецкая касается проблем тембро-оркестровой семантики, но такие вопросы вполне уместно поднимать и в работе, посвященной баянным ансамблям и оркестрам.

Система музыкальных знаков, которой оперирует «тембровая семантика», позволяет на основе собственного музыкального опыта трактовать весь комплекс средств, задействованных в построении музыкального образа. Функции такой тембровой семантики - это, с одной стороны, проявления изобразительности, картинности, колорита. Эти качества напрямую связаны с гармонией и фактурой. С другой - экспрессии (то есть эмоциональной окрашенности тембра), воспроизведение психологического состояния человека.

Если задействовать классификацию выразительности инструментов, предложенную Н. Римским-Корсаковым в «Основах оркестровки», где инструментальные группы выстроены по уровню вы- 
раженности или колористичности (от эмоционально наполненных струнных до исключительно колористических ударных), то можно констатировать, что баян-аккордеон оказался универсальным инструментом. Ему подчинены как эмоционально окрашенные проявления (кантилена, выразительное интонирование), так и колористические и изобразительные.

Колористичность в музыке XX века переросла в такое явление, как сонористика. Термины «сонорика» (от лат. sonorus - «звучный») и «сонористика» довольно близки и пока не имеют серьезных различий в определении. Так же отметим, что авторы сонорных композиций воспринимают группу из множества звуков как единый колористический или экспрессивный комплекс - сонор (по терминологии Ю. Холопова), где человеческий слух не дифференцирует отдельные элементы звуковысотной структуры. Такая техника современной композиции оперирует темброзвучностями согласно их специфическим закономерностям. Главная задача сонорных приемов - отвлечь внимание от специфически музыкального восприятия звука, нивелировать высотное значение звука и дифференциацию каждого отдельного тона.

Сонористические приемы появились еще в музыке композиторов-романтиков (Г. Берлиоз, Ф. Лист, Г. Штраус). Это в первую очередь необычные приемы игры на инструментах (удары древком смычка по корпусу, тремоло по тарелке палочками от литавр, флажолеты арфы и тому подобное), а также введением новых, преимущественно ударных, инструментов. Активно сонористические приемы стали использоваться примерно с 60-х годов XX века в творчестве А. Мессиана, Д. Лигети, К. Штокхаузена, Я. Ксенакиса, В. Лютославского, Дж. Шелси, К. Пендерецкого, Э. Денисова, С. Губайдулиной и т. д.

Удельный вес сонорных приемов в композиции может быть разным. «Само оперирование сонорными темброблоками различается по степени детализации: от широкого обобщенного письма К. Пендерецкого в его ранних произведениях к изящной звукописи Д. Лигети и Э. Денисова. Столь же индивидуальна и образная сфера сонорной музыки. От ярких энергичных звучаний в композициях Я. Ксенакиса и К. Пендерецкого к воплощению изысканных «видений», а также ирреального хаоса в музыке Д. Лигети, от повышенной экспрессии в произведениях В. Лютославского к утонченному психологизму опусов Э. Денисова» - отмечает в своей диссертации И. Остромогильский $[9,70]$. Для подобных произведений характерна визуальность в 
восприятии. Музыкальная информативность тембра растет. В то же время трактовка такой музыки зависит от собственного опыта слушателя, жизненного и музыкального.

По идее Ю. Холопова, сонорика - это музыка третьего измерения, характеристиками которой являются глубина, тембр (первое измерение - горизонталь, мелодия; второе - вертикаль - гармония). То есть сонористику можно рассматривать как особый вид музыкального мышления композитора, что задает исполнителю новые задачи по донесению музыкального текста слушателю, побуждает его к поиску новых приемов игры. Попробуем проанализировать сочинения украинских композиторов, работающих с сонорными техниками.

Интересные драматургические решения и тембровые сочетания демонстрирует Кармела Цепколенко (1955) - одесский композитор, выпускница Одесской консерватории по классу композиции (кл. проф. О. Красотова) и фортепиано (проф. Л. Гинзбург), а также аспирантуры Московского педагогического института им. Гнесиных (кл. проф. Г. Цыпина). К. Цепколенко ведет активную общественную деятельность (основатель и председатель правления международной общественной организации Ассоциация «Новая музыка», украинской секции Международного общества современной музыки (ISCM), артистический директор и член жюри многочисленных исполнительских конкурсов и фестивалей и т. д.). К. Цепколенко является автором более 70 произведений, среди которых оперы, симфонии, концерт, перфомансы, электронная музыка.

Отдельная страница творчества этого талантливого композитора - камерные сочинения для баяна соло и баянных ансамблей. История их возникновения чаще всего связана с конкретными посвящениями. Так, «Дуэль-Дуэт № 10» для баяна и виолончели написан специально для Ельзбет Мозер и Николауса Альштедта (2004 г.). На заказ Австрийского фонда культуры написано произведение «Бессилием сломанные народы... Кладбищенская музыка» для баяниста (баян, перкуссия (2 бонга, китайская коробочка) и видеошоу (фотографии кладбищ на территории бывшей Австро-Венгерской империи Л. Кристофа)) (2000). На заказ швейцарского ансамбля «Klangheimlich» написано произведение «Выход» для голоса, кларнета, баяна и фортепиано из поэзии П. Тычины, А. Блока, Т. Фонтане, Г. Аполлинера, Е. Е. Комингса (1996). Украинскому дуэту «Каданс» посвящено сочинение «Дуэль-дуэт № 5» для баяна и скрипки (1995). 
Большой вклад в пропаганду произведений в стиле «модерн-баяна» сделал украинский исполнитель Иван Ергиев (1960), выпускник Одесской консерватории по классу баяна (кл. проф. В. Евдокимова) и ассистентуры-стажировки Киевской консерватории (рук. проф. М. Давыдов), дипломант и лауреат многочисленных международных исполнительских конкурсов. Этот талантливый человек посвятил свою жизнь воплощению своей мечты - развитию отечественного «модерн-баяна». Столкнувшись, как и большинство исполнителей, с отсутствием современного репертуара для баяна, И. Ергиев решил эту проблему в творческом сотрудничестве с Кармелой Цепколенко, фактически убедив композитора в возможностях баяна как современного академического инструмента. Первое сочинение, написанное лично для И. Ергиева, - «Fa from the crowd» («Тот, кто вышел из круга») (1994) - стал знаковым, разорвав в украинской музыке круг традиционного отношения к баяну и стал основой долгого творческого сотрудничества. Сам исполнитель трактует идею произведения следующим образом: «Попытка личности «вырваться из круга», из стереотипного восприятия жизни, искусства, осознания реалий настоящего, расширить рамки бытия - это философская притча произведения». Личная заслуга И. Ергиева - не только пропаганда стиля «модерн-баян» в Украине и мире, но и активное привлечение профессиональных композиторов к созданию такой музыки. Высокий исполнительский уровень и жажда этого незаурядного человека исполнения новейшей музыки «модерн-баян» привели к тому, что украинскому исполнителю посвящаются как сольные, так и ансамблевые произведения, а сам баянист за 10 лет активного творчества осуществил около 40 премьер!

Безусловное достижение И. Ергиева - создание современных ансамблей различных составов, образовавшихся из сотрудничества с отдельными исполнителями или коллективами. Так, семейный дуэт Ергиевых (баян и скрипка - Иван и Елена Ергиевы) стал источником вдохновения и первым исполнителем многих современных произведений. Творческое сотрудничество соединило Ергиева и с камерным ансамблем новой музыки «Фрески», который был создан при одесской филармонии. И. Ергиев стал инициатором создания уникальных программ авангардной музыки и современных перфомансов с участием баяна, в частности, введение баяна в музыку для кино, театра (опера, балет) [2].

Яркая страница ансамблевого баянно-аккордеонного исполнительства - творчество Людмилы Евгеньевны Самодаевой 
(1953) - выпускницы Одесской государственной консерватории им. А. В. Неждановой (класс композиции проф. А. Красотова), члена Национального союза композиторов Украины. Композитор активно осваивает театральные (9 камерных опер, музыка к театральным спектаклям), вокально-инструментальные и вокальные жанры. Л. Самодаева стала одним из первых украинских авторов, которые активно подключились к освоению новых жанров, нового музыкального языка. Новации композитора коснулись и камерной музыки.

Особый пласт творчества Л. Самодаевой - музыка для баяна. Это преимущественно произведения для разнотембровых ансамблей различных составов. Такие ансамбли стали результатом сотрудничества композитора с исполнителями-баянистами, которые в этот период особенно остро ощущали потребность в обновлении репертуара. «Когда восходит луна» на стихи Ф. Г. Лорки для скрипки, флейты, баяна, рояля и виолончели, написанное в 1994 г., - первый опыт обращения композитора к тембру баяна. В этом произведении баян не имеет сольной партии. Его функция - удержание органного пункта.

Но, пожалуй, главная ее заслуга в инструментальном творчестве синтез двух казалось бы, несочетаемых в академической музыке полей: баянно-темперированного, что дышит силой, в каком-то смысле «заземленного», и скрипично-импровизированного, изящного, возвышенного». Ансамбль баяна со скрипкой (любимое сочетание автора) возник случайно: Л. Самодаева получила заказ на написание музыки к детскому спектаклю «По щучьему велению» (1994). Новация композитора - в решении озвучить спектакль всего двумя инструментами - баяном и скрипкой.

Алена Томленова - также представительница одесской школы. В ее творческом багаже - симфонии, месса, камерная опера по И. Бабелю, струнные квартеты, вокальные циклы, камерные жанры. Композитор активно экспериментирует с современными техниками, тяготеет к направлению «модерн-баян». Произведение «Так сказал Бог» (2005) написано для ансамбля баяна и фагота. Надо отметить, что подобное сочетание инструментов встречается впервые. Тембры двух инструментов близки, но музыкальная задумка композитора в их противопоставлении (условном столкновении божественного и дьявольского). Партии баяна поручается положительная роль Бога, фаготу - коварная роль дьявола. Драматургия рождается из конфликта двух сил, двух тембров. 
Творческие интересы Владимира Рунчака (1960), украинского композитора и дирижера, выпускника Киевской консерватории (как дирижер - класс проф. Гозулова; как баянист - класс профессора Ризоля) весьма широки: он пишет музыку для симфонического и камерного оркестра, хора, солистов, ансамблей. Среди самых известных его произведений - симфония для баяна и оркестра «Страсти по Владиславу», Fortepiano концерт, Requiem, тому подобное. Ансамбль для баяна и скрипки «Kurie eleison» («Господи помилуй») (2003) одно из произведений В. Рунчака, которое отражает поиск духовного начала путем драматических испытаний и демонстрирует авторскую манеру изложения музыкального материала. Ансамбль представляет новые возможности необычного тембрового дуэта, коснувшись темы высоких моральных размышлений и демонстрируя новый современный язык. Рунчак нашел свой личный баланс между стилистическими, технологическими ограничениями и новой свободой. В его произведениях можно услышать мужество авторского высказывания, которое выходит за границы принадлежности какой-либо отдельно взятой композиторской школе.

Анализируя современную украинскую музыкальную литературу для баянных ансамблей, можно сделать следующие выводы: тембр становится одним из важнейших факторов формообразования. Композиторы, создавая ансамбли с участием баяна-аккордеона, формируют композиционный план произведения, учитывая тембровое взаимодействие выбранных инструментов. То есть от самого начала - замысла произведения - композиция выстраивается на тембровом противопоставлении, наращивании или полифоническом сочетании различных тембров. Такой процесс можно сравнить с оркестральным мышлением композиторов-симфонистов, у которых партитура непосредственно рождается в определенных красках-тембрах. Не удивительно, что подавляющее большинство украинских композиторов, обращающихся к жанру баянного ансамбля, являются композиторами-симфонистами. Благодаря этому можно констатировать «оркестровость» как способ мышления композиторов при создании подобных ансамблей.

\section{СПИСОК ЛИТЕРАТУРЫ}

1. Давыдов М. История исполнительства на народных инструментах. Киев: Национальная музыкальная академия Украины им. П. И. Чайковского, 2005. $420 \mathrm{c}$. 
2. Ергиев И. Музыкальное искусство и культура. Одесса, 2003. 210 с.

3. Иванов Е. Гармоники, баяны, аккордеоны (духовные и материальные аспекты функционирования в музыкальной культуре Украины XIX-XX). Сумы, 2002. $71 \mathrm{c.}$

4. Имханицкий М. История баянного и аккордеонного искусства. Москва, 2006.197 с.

5. Назайкинский Е. Звуковой мир музыки. М.: Музыка, 1988.163 с.

6. Коробецкая С. Тембро-оркестровая семантика как функциональный аспект оркестрового стиля. Украинское музыковедение-57. - 61 с.

7. Кужелев Д. Художественные тенденции развития академического баянные исполнительства во второй половине XX в.: автореф. дис. ... канд. искусствед.: 17.00.01. КНУКИМ. М., 2002. 26 с.

8. Мирек А. Из истории аккордеона и баяна. М.: Музыка, 1967.193 с.

9. Остромогильский И. В. Тембро-звуковые и визуальные аспекты фактуры произведений Д. Лигети 1960-1980-х годов: дис. ... канд. искусстовед. Спец 17.00.02. Музыкальное искусство. СПб, 2012.317 с.

10. Поникарова Л. Баян в народно-инструментальном жанре Украины. Харьков: Торнадо, 2003. 104 c.

\section{REFERENCES}

1. Davydov M. (2005) The history of performance on folk instruments. Kiev: National Music Academy of Ukraine im. P. I. Tchaikovskogo [in Ukrainian].

2. Yergiev I. (2003) Musical art and culture. Odessa [in Ukrainian].

3. Ivanov E. (2002) Harmonics, accordions, accordions (spiritual and material aspects of functioning in the musical culture of Ukraine XIX-XX). Sumy [in Ukrainian].

4. Imkhanitsky M. (2006) History of accordion and accordion art. Moscow [in Russian].

5. Nazaikinsky E. (1988) The sound world of music. Moscow: Musyka [in Russian].

6. Korobetsky S. Tembro-orchestral semantics as a functional aspect of the orchestral style. Ukrainian musicology-57. [in Ukrainian].

7. Kuzhelev D. (2002) Artistic trends in the development of academic bayan performers in the second half of the twentieth century. Extended abstract of candidate's thesis. [in Ukrainian].

8. Mirek A.(1967) From the history of the accordion and accordion. Moscow: Musyka [in Russian].

9. Ostromogilsky I.(2012) Tembro-sound and visual aspects of the texture of D. Ligeti's works of the 1960-80s: Candidate's thesis. St. Petersburg [in Russian].

10. Ponikarova L. (2003) Bayan in the folk instrumental genre of Ukraine. Kharkov: Tornado [in Russian].

Стаття надійшла до редакції 15.06.2016 